been observed to pass in and out of parallel telegraph wires.

(3) They appear to be associated directly or indirectly with large quantities of energy, for they have been observed to explode with violence, and have also been seen to fuse the overhead wire of an electrical tramway.

No satisfactory explanation of ball lightning has been offered. Dr. Russell says : "Globular lightning seems to be a brush discharge taking place at the end of a column of air of higher conductivity than the neighbouring air." $\mathrm{He}$ then points out some of the difficulties of this explanation, to which others can be added; in fact, there is really nothing very similar between a brush discharge and the ball of glowing gas so frequently described. The only physical phenomena yet produced in a laboratory at all approaching ball lightning is the active nitrogen studied by Lord Rayleigh. In this case we have a mass of nitrogen subjected to an electrical discharge which continues to glow for some time after it has been removed from the field. Lord Rayleigh, however, is unable to accept this explanation of ball lightning, and all that we are able to say is that active nitrogen is the nearest physical phenomenon to ball lightning yet produced in our laboratories. Ball lightning appears always to be associated with a thunderstorm, and it is possible that the intense discharge of a lightning flash can produce some atomic change in the air or rain through which the discharge passes. If this is so, the glowing matter of ball lightning may be in a state otherwise not met with in Nature.

\title{
Unusual Forms of Crystallisation of Cementite in Steel.
}

\begin{abstract}
EMENTITE, the carbide of iron, which confers on iron the properties of steel, exists in three principal forms in hypereutectoid steels, $(x)$ the pseudodendritic form, (2) the cellular or intergranular form, and (3) the intragranular form which gives rise to the Widmannstätten structure. Pseudo-dendritic distribution arises directly from the irregular concentration of the solid solution which results on solidification. The cellular variety occurs between the grains, i.e. in the network of the grain junctions, while the Widmannstätten structure is caused by the precipitation of cementite in the interior of the grains themselves and shows evidence of the directive influence of the crystalline network of each grain.
\end{abstract}

A. M. Portevin has examined a sample of steel which has enabled him to make certain new observations in regard to these forms of cementite. These results were presented at the autumn meeting of the Iron and Steel Institute held recently in Italy. The sample was found in the hearth of a blast-furnace, and its exterior presented the characteristic concave facets peculiar to intergranular fracture. The grains of which it was composed were exceedingly well developed, their size being of the order of $\mathrm{I} \mathrm{cm}$. in transverse thickness and several centimetres in length. The specimen contained $x \cdot 22$ per cent. of carbon, $I \cdot 35$ of silicon, and $0 \cdot 17$ of phosphorus. It was, therefore, very distinctly hypereutectoid and corresponds, so far as carbon percentage is concerned, to a fairly hard cutting tool. An examination of the microstructure of this sample revealed the presence of the cellular and Widmannstätten modes of distribution of cementite, but the pseudo-dendritic form was absent.

\section{Intragranular Cementite.}

A micrographic section usually shows the cementite in needles arranged along three or four directions in each grain. This corresponds spacially with lamellæ parallel with the faces of the octahedron, and has the appearance which cementite assumes more particularly in case-hardened samples very high in carbon. In the sample examined by Portevin a different orientation of the intragranular cementite was observed. The constituent was present, not in the usual isolated rectilinear needles, but in the form of bundles of numerous very small needles, or of groups of elements crowded together. These were apparently elongated 1923 Nature NO. 2820 , VOL. I I 2$]$ analogous to the prismoids of Belaiew, grouped in masses. This is apparently the first time that intragranular cementite has been noticed with these morphological characteristics. It can, however, also be produced in steel which has been strongly case-hardened at a very high temperature and very slowly cooled. Inclusions and notably bubbles constituted centres of crystallisation around which the bundles of needles were grouped.

\section{Intergranular Cementite.}

This is customarily described and represented as enveloping the grains and appearing in a section as continuous ribbon-like filaments which do not display any characteristic shape or orientation. Howe and Levy, however, have directed attention to the needle points which impinge from the cementite network into the interior of the grains, and have raised the question as to whether these take their direction in obedience to the crystallisation orientation of the adjacent grain or of that of the network itself. They have suggested that both influences manifest themselves, and that sometimes one and sometimes the other predominates. In the present sample there is no continuous network of cementite surrounding the grains. There is a grouping of this constituent along the confines of the grain joints, the variable orientation of which can sometimes be attributed to that of the intragranular elements of cementite dispersed within each grain and sometimes appears distinctly different. In other words, the two influences remarked by Howe and Levy manifest themselves. Fig. I represents the appearance obtained after oil-quenching at $950^{\circ} \mathrm{C}$. followed by annealing at $550^{\circ} \mathrm{C}$., a treatment which causes the great bulk of the pro-eutectoid cementite, and more especially the Widmannstäten cementite, to disappear. The photograph has been taken at the junction of three grains. The needles which compose the network have in one instance different directions in regard to each grain, giving the junction the appearance of the barbs of a feather, while in the two other junctions they have an almost uniform orientation. It appears that the structural elements of the network have distributed themselves along a mean direction or have assumed a direction of their own, the influences of the orientation of each grain conflicting with each other in the neighbourhood of the junction. The needles are 
very short and it is difficult to ascertain their orientation with exactitude. The disturbance occasioned in the distribution of the structural elements which separate the grain junctions by the simultaneous influence of the varying orientations of each grain is thus manifest. Portevin remarks that some observers will not fail to interpret them as arising from the intervention of " amorphous material," whereas they

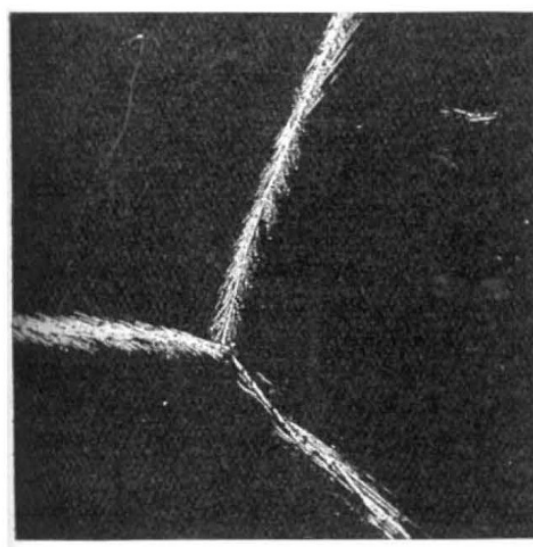

Fiti, t. - Peculiar segregation of cementite at crystal can easily be interpreted as the resultant of two forces acting in different directions. He has observed a similar instance in the case of aluminium bronze containing 90 per cent. of copper which has been hardened and annealed. Here the intergranular elements of $\alpha$ separated along the grain joints have a different orientation from that of the acicular intragranular element.

Cementite, as is well known, is exceedingly sensitive to coalescence phenomena. The author has stimulated the coalescence of the pro-eutectoid cementite of the sample by heating it for $\mathrm{I} \cdot 5$ hours at $950^{\circ} \mathrm{C}$. followed by oil-quenching, and then by one hour's annealing at $600^{\circ} \mathrm{C}$. This gives darkly-etching sorbite in which the undissolved cementite appears white and is very clearly distinguishable. Under these conditions the coalescence of the cementite prismoids is shown by a rounding of the boundaries and the splitting up of the elements constituting the bundles; but in addition an agglomeration is observed which gives the cementite a pitted appearance and is misleadingly like the eutectic of white pig-iron. (See Fig. 2.) This pseudo-eutectic appearance, due to coaléscence, appears to be a new observation and shows the intensity of the influence of surface tension on cementite at the above temperatures. The tension is, in this instance, an important morphological factor.

Another unusual type of occurrence of cementite in steel was described at the same meeting by Prof. Edwards and Mr. Pfeil. In this case, however, the phenomenon was observed in mild steel sheets, i.e. in hypo-eutectoid steels. Defects are sometimes encountered in such sheets when subjected to moderately deep stamping operations and consist of a series of corrugations in the side walls of the dish. The degree of corrugation increases on passing from the bottom to the top, and is, in all probability, due to the greater amount of cold work put upon the metal there. It was found that the microstructure of the steel consisted of two approximately equal parts : $(a)$ a very coarsely crystalline layer apparently free from carbon, and $(b)$ a finely crystalline layer in which no pearlite was present bide was segregated at the tions in irregular nodules. A section cut from the corrugated part of the dish showed very coarse severely deformed crys tals. Running round the crystal boundaries, however,

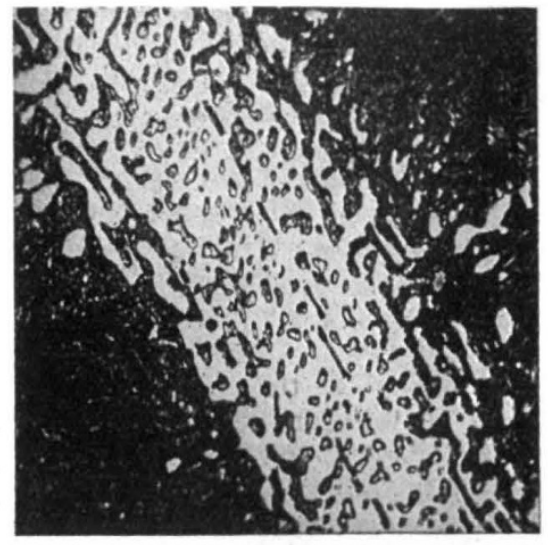
was an almost F1G. 2.-Eutectic-like appearance of cementite. $\times{ }_{500}$ continuousnet-

work of what may be termed "beaded" cementite. This constituent must have segregated from pearlite and coalesced into this form under the influence of surface tension during the annealing. Its appearance is shown in Fig. 3 at a magnification of $25^{\circ}$ diameters. So far as the writer is aware, this type of but the carcrystal junc-

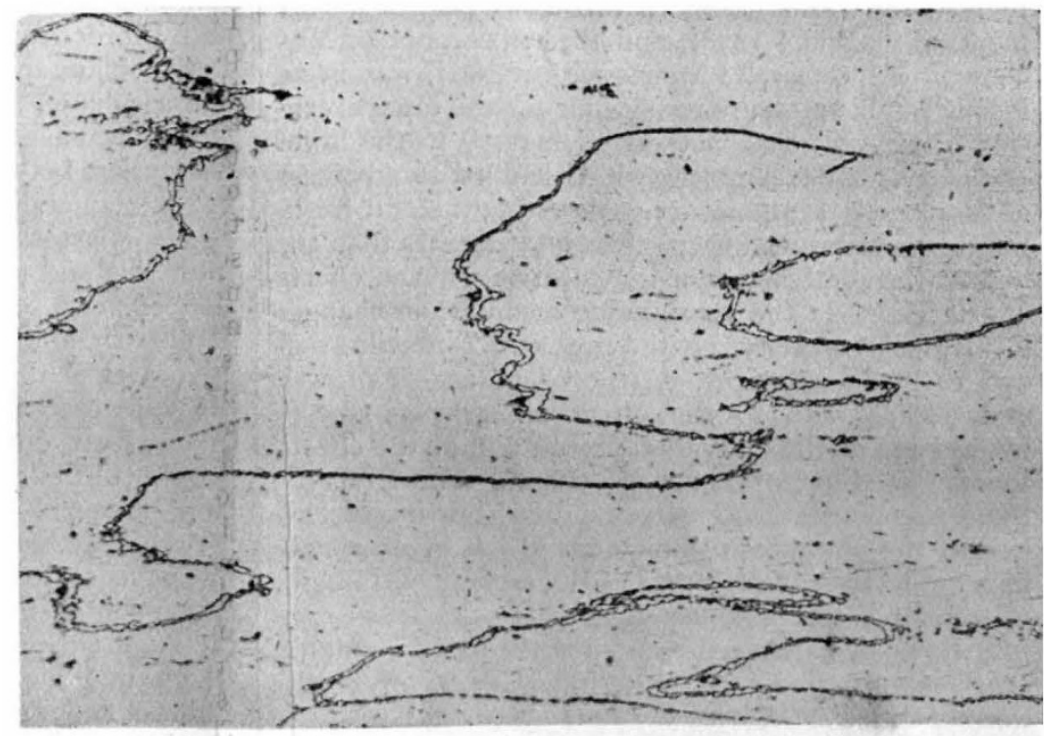

FiG. 3. - Beaded cementite at crystal boundaries of ferrite. $\times 250$. occurrence of cementite in a mild steel has not been previously described. The authors have not proposed any explanation of how it is brought about, but are endeavouring to produce it intentionally. Clearly much work still remains to be done to explain the. various forms of cementite which may and do occur in both hypo- and hyper-eutectoid steels.

H. C. H. C. 